\title{
STRATEGIES FOR SMALL ENTERPRISES NEGOTIATING WITH LARGE FIRMS
}

\author{
Ştefania Anca Stan \\ "Vasile Alecsandri” University of Bacău \\ anca_stan68@yahoo.com
}

\begin{abstract}
All around the world business is changing. All traditional business practices have been called into question as markets, customers competitors, problems and solutions have changed. As a result, business practices we once took for granted, like traditional negotiating approaches are falling by the wayside in favor of more collaborative, equally beneficial, win-win strategies. A new negotiation paradigm away from negotiating a deal and toward negotiating a relationship is needed for the twenty first century. Business can no longer stay on top by negotiating short term victories. The key to winning unbeatable, long term results is to negotiate solid, long term relationship. Smart business owners are trying to find ways to leverage their assets, and one important way is to negotiate for long - term relationships. Traditional knowledge and skills remain important. Yet global managers can better respond to global demands by learning continuously managing diversity, and developing a global mindset.
\end{abstract}

\section{Keywords}

negotiation; small business; win-win strategies; cross - cultural negotiation

\section{JEL Classification}

M10

\section{Introduction}

Negotiations occur for several reasons: to agree on how to share or divide a limited resource, such as land, or property, or time; to create something new that neither party could do on his or her own; to resolve a problem or dispute between the parties.

A new negotiation paradigm away from negotiating a deal and toward negotiating a relationship is needed for the twenty first century. Business can no longer stay on top by negotiating short term victories. The key to winning unbeatable, long term results is to negotiate solid, long term relationship.

Negotiating has changed because the definition of customer and competitor has changed. In today's world, yesterday's competitor could be today's customer. Today's is important that competitors are creating new markets by joining forces with former competitors in intense cooperation, creating shared visions, forming alliances and managing complex relationships. The definition of customer has also changed and with it the process of traditional negotiating. Customers have traditionally been the purchasers or users of products and services. Now customers may be partners sharing costs, ideas, people and risk in an effort to find new markets and solve business problems. Traditional negotiating put the customer in the role of opponent. The new world order requires each party come to the negotiating table exploring new ways to work together to create wealth.

Business requires undertaking a variety of transactions. Today companies of all sizes increasingly complete in global markets to seek growth and to maintaining their competitive edge. 


\section{The secrets of successful negotiating}

In recent years, the trend among large firms has been to merge, to form large or to outsource to remain competitive in the global market - place. Large firms, by contracting out value - added activities to smaller outside suppliers, create greater contacts between large and small enterprises. Because of their size and resources, larger firms tend to obtain more favorable agreements in dealing with smaller ones. One of the major weaknesses of smaller firms is to allow the bigger party the control of the negotiating process in the faint hope of getting sizable contracts. Larger companies, being well aware of this, encourage smaller firms in the illusion of securing substantially lucrative future business by making them accept major and immediate concessions in current deals. Unfortunately, these future orders might not materialize, or if they do, might easily turn out to be unprofitable for the small firm that has been persuaded into giving a way too many concessions. In the long term, these small companies may go out of business because of financial insolvency.

But the facts, there are many elements to the negotiating process that need to be understood by smaller companies if they are to give themselves a fighting chance against tougher ore more experienced opposition, these includes: knowing how to properly prepare; understanding the stages of the negotiating process; knowing how to create and exploit bargaining power; effective bidding and bargaining; knowing how and when to close.

\subsection{Planning and preparing for effective negotiation}

Negations are part and parcel of small business life. The first and the most important step toward successful negotiation are planning and preparation.

Negotiation is often defined as three "I"-s - an interaction between two ore more interdependent parties who perceive incompatible goals. Negotiation parties enter the negotiation because they depend on each other to fulfill some needs but also perceive the other party's interests as conflicting with their own. To reach a mutually acceptable agreement, negotiation parties have to cooperate with and understand each other. An essential component of effective preparation is to conduct a well-rounded analysis of the bargaining situation, to understand not only one's own positions, interests, priorities and alternatives, but also those of the counterparts. In a typical business negotiating, parties come together to attempt to exchange resources, or make a deal. Negotiators use distributive bargaining strategies to claim greater value for themselves, whereas they use integrative bargaining strategies to expand the pie for both parties. Negotiators who are better prepared have numerous advantages, including the ability to analyze the other party's offers more effectively and efficiently, to understand the nuances of the concession/making process, and to achieve their negotiation goals.

Good preparation means understanding one's own goals and interests as well as possible and being able to articulate them to the other party skillfully. It also includes being ready to understand the other party's communication in order to find an agreement that meets the needs of both parties.

Good preparation also means setting aspirations for negotiation that are high but achievable. Negotiators who set they sights too low are virtually guaranteed to reach an agreement that is suboptimal, while those who set them too high are more likely to stalemate and end the negotiation in frustration.

Negotiators also need to plan their opening statements and positions carefully so they are especially well prepared at the start of negotiations. It is better that negotiators prepare by understanding their own strengths and weaknesses, their needs and 
interests, the situation and the other party as well as possible so they can adjust promptly and effectively as the negotiation proceeds.

\subsection{Clear objectives}

Effective strategy and planning are the most critical precursors for achieving negotiation objectives. The first step in developing and executing a negotiation strategy is to determine one's goals. Negotiators must anticipate what goals they want to achieve in a negotiation and focus on how to achieve those goals. There are four aspects of how goals affect negotiation.

First, in negotiation, wishes are not goals. A wish is a fantasy, a hope that something might happen; a goal is a specific focused target that one can realistically plan to achieve. Second, goals are often linked to the other party's goals. The linkage between the two parties' goals defines on issue to be settled and is often the sources of conflict. Third, there are boundaries or limits to what goals can be. Goals must be attainable. Fourthly, effective goals must be concrete, specific and measurable. The less concrete and measurable our goals are, the harder it is to communicate to the other party wants and determine an offer on the table satisfies our goals.

Negotiation should never occur until specific goals have been formulated carefully. Never the less, although goals have been carefully planned, the negotiation may still fail if the parties' goals are incompatible, while the parties remain inflexible.

\subsection{Negotiator experience and abilities}

Negotiators influence the negotiation process with theirs own experience and negotiating skills. Negotiators operate within two limits: firstly, they act to increase common interests and to expand cooperation among the parties; secondly, they act to maximize their own interests and to ensure an agreement valuable to themselves.

Smaller companies especially may lack the resources to outsource negotiations, meaning their funding, licensing, supplier and distribution deals are done by executives without the necessary negotiating skills. If such people learnt to negotiate smarter it could make all the difference. Everybody needs to make deals in order to succeed. Yet negotiation skills are seldom taught or practiced.

Skilled negotiators have observant minds; sound judgment; they are always ready to listen with attention to those whom they meet; have an open, genial, civil and agreeable manner of speaking; can discover how their counterparts are feeling and thinking; and have sufficient mind control to resist the temptation to speak before thinking. Negotiators should thoroughly understand the purpose of the negotiations before going overseas.

Good negotiators should also know the history, culture, laws, customs and government of the country they are dealing with as well as have some knowledge of the particular counterparts they will be working with.

Good negotiators need to be adaptable. They do not become wedded to static approaches or strategies. They remain vigilant on the real issues from start to finish, all the while absorbing information about their counterpart's habits, speaking and presentation patterns, and personal style. They monitor themselves as well, making sure to avoid mere reaction to choices the other side presents.

This level of performance, not easily achieved, is at the heart of what separates the skilled negotiator from the amateur. Great negotiators often go unnoticed. They are not interested in winning or glory. They have an attitude of mind which is focused on the hard work of building agreements and protecting the work through the necessary confidentiality which follows. 


\subsection{Responding when the other side has more power}

Other things being equal, when power is unequal, the more powerful party can achieve his goals more readily. Power imbalances in negotiation can represent clear dangers to the satisfaction of the needs of booth parties and to the collaborative process. First, large firms tend to pay little heed to the needs of small enterprises, which either don't get their needs met ore use disruptive, attention - getting tactics that make collaboration very difficult. Second, small enterprises are not usually in a position to trigger and advance an integrative process. Integrative negotiation requires a tolerance of change and flexibility, which often requires negotiators to give up some control over outcomes. When dealing with large firms, small enterprises have at least four alternatives. They can: protect themselves; cultivate their best alternative to a negotiated agreement (BATNA); formulate a "trip win alert system"; correct the power imbalance.

Negotiators can protect themselves by keeping in mind that they have real interests that negotiation may be the preferred approach of achieving those interests, and that excessive accommodation to the high- power party will not serve them well over the long term. In other words, small firms should remember their resistance point and try to stick to it. That said, while knowing the resistance point will provide a clear measure of minimum acceptability (lower price), too strict adherence to it may deprive negotiators of creativity and flexibility, which are critical components to the design of an integrative outcome. It may also limit their ability to use information that emerges during the exchange. Thus, large firms need to be protective of their bottom line but also open to creative approaches that may allow them to achieve their interests in other ways.

When in the low-power position, it is very important that small firms cultivate their BATNA, which represent the best outcome that they can accomplish without the current negotiation. One alternative, the best alternative to a negotiated agreement (BATNA), is especially important because this is the option that likely will be chosen should an agreement not be reached. Negotiators need to be vigilant about their BATNA. They need to know what their BATNA is relative to a possible agreement and consciously work to improve their BATNA so as to improve the deal. Negotiators without a strong BATNA may find it difficult to achieve a good agreement because the other party may try to push them aggressively, and hence they to forced to accept a settlement that is later seen as unsatisfying.

A clear BATNA may also be reinforced by additional measured. Low power negotiators are advised to formulate a trip wire alert system that serves as an early warning signal when bargaining enters the warning zone close to the walkway option or the BATNA. The trip wire tells the negotiators to exercise special caution and pay increased attention to the negotiation in progress. Given that negotiations often become intense and engrossing at such points, it might be appropriate to assign a conegotiator to attend to the warning zone and to notify the involved negotiator at the critical time.

The fourth option for dealing with more powerful parties is to correct the imbalance. Three approaches to this are possible: low-power parties taking power, high-power parties giving power, and third parties managing the transfer and balance of power. The first approach, power-taking, is typically not feasible in negotiations. Using disruptive or attention-getting actions to try to assume power typically contributes to a distributive exchange, generating in-kind responses from the high-power party. The second approach is for the high-power party to transfer power to the other party. Such actions include sharing resources, sharing control over certain processes or outcomes, focusing on common interests rather than solely on the high-powered party's 
interests, or educating the low-power party about what power she does have to use it more effectively.

\section{Negotiation in international market}

As everything is becoming globalized so small companies are also interested in expanding their business outside the country to make them globalized. Companies of all types and sizes, and in all types of industries, enter into international business transactions. Small companies are becoming increasingly active in international trade and investment. The reason why small companies are preferring for doing business across the country is that they have good opportunities and incentives and also they can obtain foreign currencies, they can beat the competition, and also they can achieve the economies of scale.

All international transactions are the product of a negotiation - the result of deal making. An international deal is a continuing negotiating between the parties to the transaction as they seek to apply their contract to unforeseen situations and to adjust their relationship to a changing international environment. International negotiations are influencing by the environmental context. Small business need to identify and controlling the factors in the environmental context that make international negotiations more challenging that domestic negotiations. Those factors are: political and pluralism; international economics; foreign governments and bureaucracies instability; ideology and culture.

- Legal pluralism. Firm conducting business in different countries is working with different legal and political systems. There may be implications for taxes than an organization pays, labor codes or standards that must be met, a different code of contract law and standards of enforcement. Negotiators should be fully briefed about relevant legal aspects of the countries involved before coming to agreement. This will ensure that the final agreement does not contain any provision that cannot be implemented because it is legally prohibited.

- Political pluralism. A thorough review of the political environment of the party's country witch whom negotiation is planned must proceed the negotiation process. An agreement may be negotiated that is legal in the countries involved and yet may be not politically prudent to implement.

- International economics. A global negotiation may involve financial transfers across national lines to deals. The exchange value of international currencies naturally fluctuates, and this factor must be considered when negotiating in different countries. The risk is typically greater for the party who must pay in the other country's currency. Any change in the value of a currency can significantly affect the value of the agreement for both parties, changing a mutually valuable deal into a windfall profit for one and large loss for the other.

- Foreign governments and bureaucracies. Countries differ in the extent to which the government regulates industries and organizations.

- Instability. The challenge for international negotiators is to anticipate changes accurately and with enough lead time to adjust for their consequences. Therefore, small business facing unstable circumstances should include clauses in their contracts that allow easy cancellation or neutral arbitration, and consider purchasing insurance policies to guarantee contract provisions. This presumes that contracts will be honored and that specific contract clauses will be culturally acceptable to the other party. 
- Ideology. Ideological clashes increase the communication challenges in international negotiations in the broadest sense because the parties may disagree at the most fundamental levels about what is being negotiated.

- Culture. Cultural diversity has become one of the most critical issues in negotiation. Doing business across national boundaries requires interaction with people nurtured in different cultural environments. People from different cultures appear to negotiate differently. In addition to behaving differently, people from different cultures may also interpret the fundamental processes of negotiations differently. For example, people in some cultures approach negotiations deductively (they move from the general to the specific) whereas people from other cultures are more inductive (they settle on a series of specific issues that become the area of general agreement). In some cultures, the parties negotiate the substantive issues while considering the relationship between the parties to bee more or less incidental. In other cultures, the relationship between the parties is the main focus of the negotiation, and the substantive issues of the deal itself are more or less incidental.

International negotiators needs to be familiar with the cultural traits of the country with which they want to negotiate.

\section{Conclusion}

Being small companies is not easy, especially when most of the dealings are with much larger companies. Expansion into new markets, access to resources, knowledge and skills, and financing opportunities are just some benefits a small firm can gain by successfully doing business with a big company.

For the small business owner or entrepreneur, skillful negotiating can mean the different between staying in business and bankruptcy. In is important for small business companies to understand that the negotiating process does not end with the agreement, instead it is the beginning of a business relationship. Success in the long run does not result from one single deal, but rather from a continuous process of maintaining a co-operative business environment. The key to winning unbeatable, long term results is to negotiate solid, long term relationship.

\section{References}

Cellich, C., Joein, G., (2012), Global Business Negotiations Across Borders. Practical Solutions, New York, Business Expert Press.

Hendon, W.D., (1996), Cross - Cultural Business negotiations, London, Greenwood Publishing Group.

Lewicki, R.J., Saunders, D.M., Barry, B., (2006), Negotiation, New York, The McGraw-Hill Companies, Inc.

O’Neil, J.M., (2013), Negotiation Strategies and Tactics for Small Business, London, Raging Zebra Publishing. 